$\S=-1$

\title{
Quasi-Static Indentation Properties of Aluminium Foam-Frp Sandwich Panel
}

\author{
Ummu Raihanah Hashim, Aidah Jumahat", Muhammad Fashan Md Ghazali \\ Faculty of Mechanical Engineering, Universiti Teknologi MARA, 40450 Shah Alam, Selangor, Malaysia \\ *Corresponding author E-mail: aidahjumahat@salam.uitm.edu.my
}

\begin{abstract}
Synthetic FRP have been used for many years in wide applications owing to their versatility and good performance. However, environmental problems caused by extensive use of polymeric materials arise mainly due to lack of landfill spaces and depletion of finite resources of fossil raw materials, such as petroleum or natural gas. Hence, materials derived from natural products are emerging as potential substitutes for petroleum-based material. The usage of natural fibre reinforced polymer (NFRP) composite have triggered considerable interest to explore the usefulness of this material. Excellent energy absorption of sandwich-structured composite made it a versatile structure used in various industries such transportation, automotive, building construction and marine. On top of that, the research data on aluminium foam as a core material in sandwich panel are limited and need to be further studied. This research is aimed to determine the quasi-static indentation properties of Basalt Fibre Reinforced Polymer/Aluminium Foam (BF-AF) sandwich panel and compare with the properties of Glass Fibre Reinforced Polymer/Aluminium Foam (GF-AF) sandwich panel. In this study, BFRP and GFRP composites with nanosilica were fabricated using vacuum bagging method. Aluminium foam was used as a core in the sandwich panel structure. The quasi-static indentation tests were performed using $10 \mathrm{~mm}$ indenter and the specimen size was $50 \mathrm{~mm} \times 50 \mathrm{~mm}$ with thickness of $3 \mathrm{~mm}$. The effect of aluminum foam on indentation properties were studied. The results showed that the addition of nanosilica enhanced the energy absorption, depth of penetration and damage area of the composites. The indentation properties of BF-AF were higher than those of GF-AF sandwich panel composites. Therefore, this research contributes to a new knowledge on the properties of aluminium foamFRP composite materials.
\end{abstract}

Keywords: aluminium foam; basalt fibre reinforced polymer; sandwich structure; impact resistance properties.

\section{Introduction}

Sandwich structures are widely being used in aircraft, automotive, aerospace and marine industries where lightweight materials with high in-plane and flexural stiffness are required [1]. It is constructed based on low weight and thick core material bonded with two thin and stiff face sheets [2]. According to Lin et al. high efficiency sandwich panel is a design that can achieve the least mass to carry optimum load capacity [3]. However, a wide range of projectile shapes, sizes, and velocities during service and maintenance life are likely to be a threat to this structure. The structure itself is less prone to large reduction in the mechanical performance when in contact with out-of-plane impact forces especially low-velocity impact. Concentrated indentation forces are the major concerns that need to be advised on the usage of sandwich structures [4].

The structure of core can be in the form of foams or honeycombs. The selection of core materials is important to retain the effectiveness of sandwich structure. Core materials must be strong enough to resist compressive and crushing loads as well as shear forces imposed on the panel [5]. Development of a new material based on the sandwich structures is needed to enhance the versatility of this structure. This has encouraged many researchers to investigate various types of high strength and lightweight materials. These investigations lead to porous metal such as aluminum foam which has an excellent stiffness to weight ratio.
Aluminium foam is a cellular structure of aluminum with a large volume fraction of gas-filled pores. Aluminium foams are widely used in automotive and aerospace industries as core materials for sandwich structures due to their ultra-lightweight and other attractive mechanical properties. Besides that, it also has an efficient energy absorption property, low density, high ductility, low thermal conductivity and competitive cost. Foam cores have many advantages such as increased support surface for bonding with the face sheets, low thermal conductivity properties, an adjustable density, high ductility, low thermal conductivity and competitive cost [6]. In the aspect of nanofiller addition, nanosilica particles increases the impact resistance as well as the impact energy up to $60 \%$ [7]. The addition of nanosilica could increase the interfacial bond between fibres and polymer as well as the stiffness.

The properties skin material for sandwich panel constructions or also called face sheet consists of a thin material with high specific strength and stiffness. FRP composite exists differently depending on the types of material used. Glass-FRP and Carbon-FRP are mostly used as face sheet in the construction of sandwich panel. A study on the impact properties on Glass-FRP and Carbon-FRP has been conducted and it was found that the forces during quasi-static indentation are similar in both laminates but GFRP shows a higher stress due to their greater deformation [8].

Many researches have been carried out based on the reinforcement of natural fibres. Basalt fibres are originated from volcanic rocks; crushed into particles and threaded into the form of fibre [9]. Nat- 
ural fibres have high potential to substitute synthetic fibres. For example, Bak and Kalaichelvan [10] found that BFRP laminates absorbed 28\% more energy compared to GFRP when impact tests were done under different temperature.

The purpose of this research is to investigate indentation properties of the aluminum foam-FRP composite material. It is expected that the addition of aluminum foam could enhance the energy absorption, depth penetration and surface damage of FRP. It is also expected that the addition of nanosilica will enhance the energy absorption, depth penetration and surface damage of nanomodified FRP composite.

\section{Methodology}

\subsection{Material}

A commercial open-cell aluminium foam supplied by Innovative Putrusion Sdn.Bhd was used as a core in the sandwich panel structure and cut to $50 \mathrm{~mm} \times 50 \mathrm{~mm}$ with $30 \mathrm{~mm}$ thickness. The BFRP and GFRP were fabricated using vacuum bagging method. Woven basalt and glass fibre were used with epoxy resin (Miracast 1517 A/B) supplied by Miracon Sd. Bhd. was used as a matrix and nanosilica as a filler. Three different percentage of nanosilica was used $(5 \mathrm{wt} \%, 10 \mathrm{wt} \%$ and $15 \mathrm{wt} \%)$ to fabricate the FRP composite. The open-cell aluminium foam was then attached with face-sheets (FRP composites) at the top and the bottom using nanosilica epoxy paste. There are two types of face-sheets was used; BFRP and GFRP with thickness $2 \mathrm{~mm}-3 \mathrm{~mm}$. Table 1 shows the list of material used in this research.

\subsection{Fabrication of Sample}

The nanosilica gel was weighted at three different weight percent which are $5 \mathrm{wt} \%, 10 \mathrm{wt} \%$ and $15 \mathrm{wt} . \%$ to be mixed with epoxy. The nanosilica gel and epoxy were then stirred for one hour at $400 \mathrm{rpm}$ using mechanical stirrer. The nanomodified mixture was poured onto the woven fibre. The FRP composite was vacuumed for 60 90 minutes to remove the entrapped air by vacuum bagging method. The FRP laminates was then left to cure for 24 hours to ensure the complete curing process.

BFRP and GFRP composite sandwich panels were cut into a size $50 \mathrm{~mm} \times 50 \mathrm{~mm}$ to be used in quasi-static indentation test. FRP and aluminium foam were bonded together using nanosilica epoxy paste. Nanosilica epoxy paste consists of resin and hardener. To fabricate the sandwich panel, first, the face sheet and core must be clean and dry to ensure the nanosilica epoxy paste adhere effectively. The mixture was applied to the face sheets and core and bonded carefully. In other to ensure the strong adhesion in between the core and face-sheets, the samples were put under $1 \mathrm{MPa}$ pressure and was cured at the room temperature for 24 hours before can be used for testing.

\subsection{Density Test}

Density test was conducted using Archimedes principle for each composite. The density of sample was obtained using Equation (1) The density test was applied to floating and submerged bodies. There were five samples of the specimen for each nanofiller weight percentage which were tested to get the average density of specimen.

$$
\rho=\frac{A}{A-B} \times\left(\rho_{0}-d\right)+d
$$

Where,

$\rho$ sample $=$ Density of sample $\left(\mathrm{g} / \mathrm{cm}^{3}\right)$

$\mathrm{A}=$ Weight in air $(\mathrm{g})$

$\mathrm{B}=$ Weight in water $(\mathrm{g})$

$\mathrm{d}=$ Density of air (approximate $0.001 \mathrm{~g} / \mathrm{cm}^{3}$ )

$\rho$ water $=$ Density of water $\left(\mathrm{g} / \mathrm{cm}^{3}\right)$

\subsection{Quasi-Static Indentation Test}

The quasi-static indentation tests on the sandwich panel were conducted using Universal Instron testing machine according to the ASTM standard D6264. 10mm indenter size was used and specimen size are $50 \mathrm{~mm} \times 50 \mathrm{~mm}$ with thickness $32 \mathrm{~mm}$. The load was applied to the specimen at constant rate velocity of $5 \mathrm{~mm} / \mathrm{min}$. The force applied continuously until the final failure of the specimen. The flat square composite panel was subjected to a concentrated load by slowly compressing a displacement-controlled indenter into the specimen surface. Graph of contact force over displacement was recorded and total energy absorption during indentation was calculated based on area under the graph.

\subsection{Microstructural Analysis}

The fractured samples were observed under optical microscope to determine the fracture mechanism. The damage specimen was cleared from dust to obtain the clearer image. Then, the specimen was placed under the microscope lens.

\section{Results and Discussion}

\subsection{Density}

The density of unmodified and nanomodified BFRP and GFRP was recorded in Table 1. The density of both FRP composite increased as nanosilica increased. Besides that, by comparing the density of BFRP with GFRP composites for all system, it was observed that BFRP have a higher density than GFRP composites with $3.32 \%, 3.24 \%, 4.77 \%$ and $5.74 \%$ for $0 \mathrm{wt} \%, 5 \mathrm{wt} \%, 10 \mathrm{wt} \%$ and $15 \mathrm{wt} \%$ respectively.

Table 1: Density of fabricated specimens

\begin{tabular}{|c|c|c|}
\hline Nanosilica content (wt\%) & BFRP & GFRP \\
\hline 0 & 1.458 & 1.411 \\
\hline 5 & 1.471 & 1.423 \\
\hline 10 & 1.508 & 1.436 \\
\hline 15 & 1.551 & 1.462 \\
\hline
\end{tabular}

\subsection{Quasi-Static Indentation}

The results of quasi-static indentation test for BFRP and GFRPaluminium foam sandwich panel are tabulated in Table 2 and 3. The load was applied to constant rate velocity of $5 \mathrm{~mm} / \mathrm{min}$ using an indenter with $10 \mathrm{~mm}$ in diameter. The energy absorption in this test was calculated based on the area under the graph of the compressive load against the compressive extension. 
Table 2: Quasi-static indentation results of BFAF sandwich panel

\begin{tabular}{|c|c|c|c|c|}
\hline Nanosilica content (wt\% & Compressive extension (mm) & Compressive load (kN) & Compressive stress (MPa) & Energy absorbs $(\mathrm{J})$ \\
\hline 0 & 22.896 & 12.935 & 5.174 & 132.388 \\
\hline 5 & 26.121 & 13.683 & 5.473 & 180.658 \\
\hline 10 & 26.403 & 15.161 & 6.064 & 242.079 \\
\hline 15 & 28.187 & 19.853 & 7.941 & 283.024 \\
\hline
\end{tabular}

Table 3: Quasi-static indentation results of GFAF sandwich panel

\begin{tabular}{|c|c|c|c|c|}
\hline Nanosilica content (wt\% & Compressive extension ( $\mathrm{mm}$ ) & Compressive load $(\mathrm{kN})$ & Compressive stress (MPa) & Energy absorbs $(\mathrm{J})$ \\
\hline 0 & 19.563 & 8.723 & 3.489 & 65.108 \\
\hline 5 & 20.363 & 10.370 & 4.148 & 84.891 \\
\hline 10 & 23.000 & 13.063 & 5.225 & 130.728 \\
\hline 15 & 24.100 & 13.583 & 5.433 & 161.844 \\
\hline
\end{tabular}

Compressive load for both BFAF and GFAF sandwich panel show that $15 \mathrm{wt} \%$ nanosilica has the highest value with 19.853 and $13.583 \mathrm{kN}$, respectively. The percentage difference between the nanomodified (15wt\%) BFAF and GFAF sandwich panel compared to unmodified are $54.48 \%$ and $55.71 \%$ respectively. Similarly, $15 \mathrm{wt} \%$ nanosilica for both sandwich panels have the highest energy absorption capacity as proven by graph in Fig. 1 and 2 where the area under the graph are larger for $15 \mathrm{wt} \%$ as compared to other system. This deduced that nanosilica content in FRP composites improved energy absorption, strength and damaged resistance of composite.

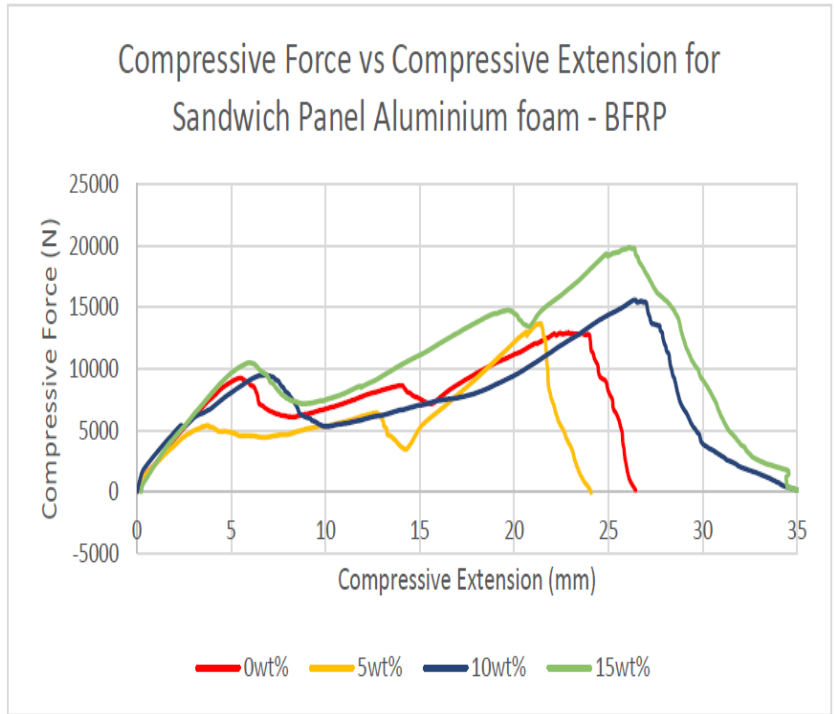

Fig. 1: Compressive force against compressive extension for BFAF sandwich panel

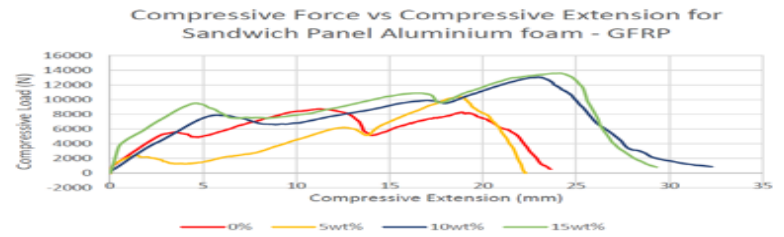

Fig. 2: Compressive force against compressive extension for GFAF sandwich panel
Fig 3 shows the comparison in energy absorption between BFAF and GFAF sandwich panels. It shows that basalt fibre has higher energy absorption capacity (as much as more than $80 \%$ increment) compared to glass fibre composite. This is a good indicator to use basalt fibre as the alternative material for synthetic glass fibre composite. The addition of nanosilica into the composite also contributed to the improvement of composite properties.

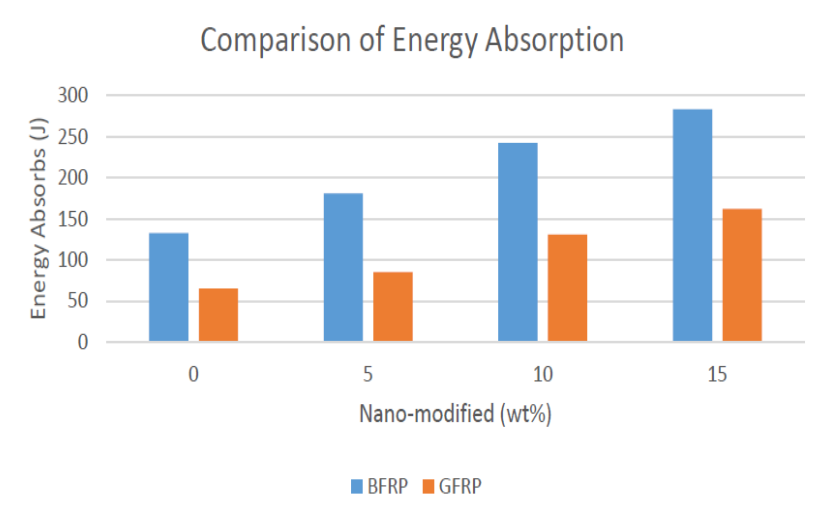

Fig. 3: Comparison in energy absorption for BFAF and GFAF sandwich panel with different nanosilica contents.

\subsection{Damage Characterisation}

Table 4 shows the damage surfaces of specimens undergo quasistatic indentation test. Both BFAF and GFAF sandwich panel failed under several failure modes, namely face sheet indentation, core crushing, fibre breakage, fibre crack and face sheet bending. On the upper side of specimen, fibre breaking can be seen on both BFAF and GFAF specimens with totally indented and punctured through the face sheet where localized deformation can be seen for GFAF specimen. Meanwhile, bottom face sheet of BFAF specimen did not show total deformation, but face sheet bending occurred without punctured through it. As for GFAF, the deformation and failure on the bottom face sheet were seen as fibre crack and fibre breakage. 


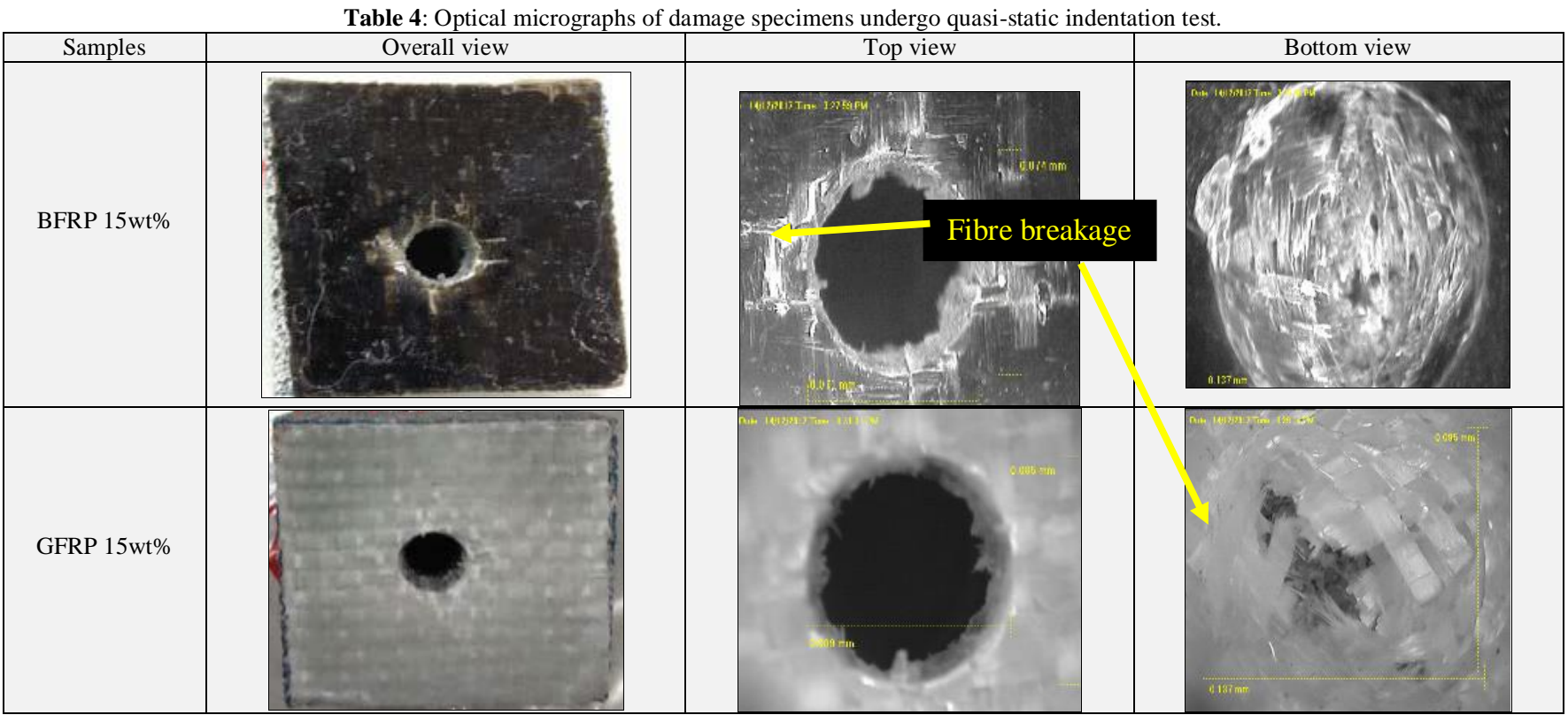

\section{Conclusion}

Quasi-static indentation test was conducted to investigate the energy absorption of BFAF and GFAF sandwich panel composite. Both BFRP and GFRP incorporated with four different weight percentage of nanosilica were successfully fabricated and used to compare their energy absorbing capacity. The physical and mechanical properties in term of quasi-static indentation of the unmodified and nanomodified BFAF and GFAF sandwich panel were evaluated. $15 \mathrm{wt} \%$ of BFAF and GFAF sandwich panel show the highest value in energy absorption capacity with more that $60 \%$ improvement compared to unmodified system. The stiffness and energy absorption of the composites were enhanced by the existence of nanosilica. BFAF sandwich panel shows better performance than GFAF sandwich panel with more than $80 \%$ improvement in energy absorption capacity. It also can be concluded that the basalt fibre is a promising material that suitable to be used as an alternative to glass fibre owing to its good mechanical properties.

\section{Acknowledgement}

The authors would like to thank the Institute of Research Management and Innovation (IRMI) UITM, Ministry of Education Malaysia and Institute of Graduate Studies (IPSIS) for the financial supports. The research is conducted at the Faculty of Mechanical Engineering, Universiti Teknologi MARA (UiTM), Malaysia under the support of Research Entity Initiative (REI) grant no: 600-IRMI/DANA 5/3/REI (11/2017).

\section{References}

[1] Z.B.Li at al., "Indentation Behavior of a Closed-Cell Aluminum Foam at Elevated Temperatures", Key Engineering Materials, Vol. 535-536, pp. 219-222, 2013

[2] S. Ahmed, S. Lee, C. Cho, and K. K. Choi, "Experimental Study on Low Velocity Impact Response of CFRP-Aluminum Foam Core Sandwich Plates," 18th International Conference on Composite Materials, 2011.

[3] H. Lin, H. Luo, W. Huang, X. Zhang, and G. Yao, "Diffusion Bonding in Fabrication of Aluminum Foam Sandwich Panels," Journal of Materials Processing Technology, Vol. 230, pp. 35-41, 2016.

[4] E. A. Flores-Johnson and Q. M. Li, "Experimental Study of the Indentation of Sandwich Panels with Carbon Fibre-Reinforced Poly- mer Face Sheets and Polymeric Foam Core," Composite: Part B, Vol. 42, No. 5, pp. 1212-1219, 2011.

[5] Aneta Krzyżak, Michał Mazur, Mateusz Gajewski, Kazimierz Drozd, Andrzej Komorek, and Paweł Przybyłek, "Sandwich Structured Composites for Aeronautics: Methods of Manufacturing Affecting Some Mechanical Properties," International Journal of Aerospace Engineering, 2016.

[6] García-Moreno et. al., Commercial Applications of Metal Foams: Their Properties and Production. Materials, Vol 9, No 2, 2016.

[7] M. Conradi, M. Zorko, A. Kocijan, I. Verpoest, "Mechanical Properties of Epoxy Composites Reinforced with a Low Volume Fraction of Nanosilica Fillers", Materials Chemistry and Physics, Vol 137, No 3, pp 910-915, 2013

[8] J. Bieniaś "Comparison of Polymer Composites Behavior To LowVelocity Impact and Quasi-Static Indentation”, Vol. 3, pp. 155159, 2013.

[9] Fiore, T. Scalici, G. Di Bella, and A. Valenza, "A Review on Basalt Fibre and its Composites," Composite: Part B, Vol. 74, pp. 74-94, 2015.

[10] Mohamed Bak and Kalaichelvan K., "Experimental Study on the Mechanical Characterization of Glass-Basalt Fiber Reinforced Polymer (FRP) Composites," International Journal of Materials Science and Engineering, Vol. 4, No. 1, pp. 46-53, 2016. 